\title{
Erratum zu: Soziale Ungleichheit, Gesundheit und Bildungserfolg
}

\section{Die intergenerationale Transmission von Bildungschancen durch Gesundheit}

\section{Erratum zu:}

\section{J.Tuppat, Soziale Ungleichheit, Gesundheit und Bildungserfolg, Gesundheit und Gesellschaft, https://doi.org/10.1007/978-3-658-31425-5}

Ein technischer Fehler im Produktionsablauf hat dazu geführt, dass das Buch zunächst mit 2021 als Copyright Jahr veröffentlicht wurde. Das Copyright Jahr ist 2020. Dies wurde nachträglich korrigiert. 